\title{
Enlightenment of Hayek’s Institutional Change Idea on Institutional Innovation
}

\author{
Juping Yang \\ School of Public Affairs, Xiamen University, Xiamen, 361005, China
}

[Abstract] Hayek's institutional change idea is derived from its spontaneous order view, his cultural evolution theory reveals the generative mechanism of institution and his legal theory explains the institutional formation logic from individual behavior to social order. Hayek's institutional change theory intrinsically includes the tension between evolution and rationalism, individualized method and holistic method, individual liberty and social order. We should distinguish and comprehensively consider the change of formal institution and informal institution and comprehensively analyze and grasp the relationship between individual liberty, institution and social order combined with the different top-down and bottom-up thinking mode and by comprehensively using the individualism and holism method to better guide the institutional innovation.

[Key words] Institutional change, spontaneous order, Hayek

\section{Hayek's institutional change idea}

1. Spontaneously evolutionary order view: institutional formation logic

Hayek thinks the formation of social institution is a spontaneous evolution process. In his view, "people's rationality cannot predict the future or construct the future of rationality after liberation. Many Utopian construction plans are valueless because they are made by the theorists that presuppose that we have knowledge". Human's experience and habits as well as the mutual adaptation between humans and between human and environment in action are the important factors for the formation of human's social order. However, the experiences and habits that constitute the foundation of code of conduct are spontaneous and not rationally realized by the human. The ideal institutional formation mode is a spontaneous evolution path and "even is the result of the spontaneous but irresistible development of some obvious principles." "Those complex and seemingly artificial-design policy plannings are almost not the result of artificial design or political wisdom.”

2. Cultural evolution theory: institutional change mechanism

Hayek explains its institutional change mechanism by the development of human civilization in The Constitution of Liberty. He thinks the human civilization is gradually formed and developed by "trial and error procedure", "the survival of the successful" and "cumulative growth" of people in the social communication. This 
process, similar to the biological evolution process, is the product of continuous trial and error and spontaneous concept correction of generates in the interaction between human and the nature and in the social communication between humans. In the specific historical period, the human cannot fully communicate with each other, comprehensively master all the knowledge and judge which knowledge is superior due to the limitation of communication method and scope, technical problem and other reasons. The different knowledge competes with each other equally in the society and then is finally spread and developed after getting the social identity by "survival of the fittest". In the social development, the knowledge is continuously accumulated and corrected.

Hayek's institutional change mechanism is essentially the free competition market mechanism. "As people give their destiny to the market, a civilization can make the previous process, otherwise it is impossible.” The formation and change of social institution are embodied as the unconsciousness of individual behavior due to the "invisible hand". The institutional change is a process of social choice. The random choice mechanism may be one from a large number of different forms, thus leading to the uncertainty of the result of institutional change; the competitive mechanism shows that the collective interests of social order in formation are essentially decided by the competitive choice mechanism.

3. Legal theory: social institution and social order

In Hayek's eyes, the social institution is often expressed as social rules and certain social order is always associated with the corresponding social rules. Hayek divides the social order into "spontaneous order" and "organizational order" and the social rules into internal rules (rules of conduct) and external rules (organizational rules). The internal rules (code of conduct) and external rules (organizational rules) correspond to the "law of liberty" and "law of legislation" in Hayek’s legal theory. Compared with the "external rules" formulated by the authority organs, the spontaneously evolutionary “internal rules” are the "real law” in Hayek's heart. Hayek thinks the individual often yields to the individual authority in the organizational order; the individual often yields to the reasonable conduct rules with a consensus in the spontaneous order. Hayek also thinks to ensure the liberty and order of the society, the external rules (organizational rules) are not desirable and the spontaneously evolutionary internal rules (rules of conduct) are the core of ideal spontaneous order.

\section{Inherent tension of Hayek's institutional change idea}

1. Evolutionary rationalism and constructive rationalism: collision of two logics

Hayek systematically discusses the evolution nature of culture, morality, law, social institution and language in his works, thus forming a perfect evolutionary rationalism theory. He firmly opposes to the constructive rationalism, but he doesn't wipe out it, but speaks highly of the function of construction rationalism in the daily life, formation of rules and other aspect, thus avoiding misunderstanding or partial understanding of his theory. 
Therefore, the constructive rationalism in his theory is inevitable.

Hayek points out that the error of constructive rationalism lies in its exaggeration of the role of rationality, trying to make everything yield to the rationality. However, seeking for the limit of the role of rationality and overcoming the "impulsion" of making rationality govern everything are also an use of rationality. In addition, the rationality is still the main basis for our prudent action in our daily life and the choice of individual behavior and the organizational design cannot leave the constructive function of rationality. "The rationality can guide people to criticize and improve the traditions. The traditions can be optimized and improved by the social spontaneous activity and people's rational deliberation.” Some scholars think the evolution rationalism and the construction rationalism in Hayek's theory are contradictory, which is outstanding in theoretical character. On one hand, Hayek's social theory with regard to the humanity and the nature of social order makes him vigorously advocate the deeply rooted anti-rationalistic liberalism; on the other hand, Hayek tries to defend this proposal according to a complete set of regulative rules, which makes him solve the problem concerning the demonstration of liberal justice theory in a rational way. That is, Hayek's evolutionary rationalism theory is essentially the result of rational demonstration and construction. Actually, Hayek really firmly opposes to the rationalistic constructive theory that conducts holistic design and planning of the society, with planned economy and central totalitarianism as the characteristics, rather than the prudent, progressive and preferential constructive rationalism.

2. Individualism and holism: methodological dualism

All in all, Hayek prefers the individualism methodology and holds a negative attitude toward the holism methodology. However, in The Constitution of Liberty and other works, we can see that Hayek examines the social order by both individualism and holism method, thus directly leading to the formation of his social order dualism theory. He discusses the internal rules (rules of conduct) by the analysis paradigm of individualism and the external rules (organizational rules) by the analysis paradigm of holism. The internal rules (rules of conduct), that is, "the law in a strict sense", are the recognized rules formed spontaneously by individuals pursuing the maximization of their interests in the long-term cultural evolution process and the external rules (organizational rules) are those formed according to the will of organization or governors for a certain purpose by means of order-obedience. The evolution of social order is the result of the interaction of internal rules (rules of conduct) and external rules (organizational rules). Hayek, who advocates the individualism methodology and the analysis paradigm of individualism, has realized that the whole is not the simple addition of individual, but fails to answer the question with regard to the interaction and mutual transformation between the individual and the whole, such as the transformation of individual choice mechanism and collective interest choice mechanism in the institutional change mechanism. 
3. Individual liberty and social order: coordination and balance between individual and the society

The problem with regard to the relationship between the individual and the society, specifically, individual liberty and social order, has always been one of the basic problems of social theory. In answering how the individual liberty becomes the "spontaneous order" of the society, that is, how to obtain the coordination and balance in the guarantee and perfection of individual liberty and the development of stable social order, Hayek thinks the transformation of individual liberty to the social order should be a process of gaining consensus and recognition by the liberal and equal interaction between individuals, rather than obeying the rationality of a small number of elites and adopting the institutional design method of compulsory change. In his view, the "rational construction" process of social order is that a small number of elites draw the corresponding rational conclusion after the criticizing and reflecting the society and then subvert the traditions and form the new social order by compulsory legislation, publicity and implementation. This constructive method often sacrifices the individual liberty, which is unfavorable to the development of individual recognition and also the knowledge innovation and accumulation of the society. Hayek advocates that the formation of social order should rely on the construction of "evolutionary rationality”. This is a natural evolution process from individual rationality to social rationality, in which the individuals gradually form a consensus and gain recognition in the equal interaction, which is the development process of the individual learning, experience and knowledge and also the progress process of human knowledge and civilization. In the process, the individual liberty is not hurt.

From the essence of the relationship between individual behavior and social order, the social institution is the product of the interaction between individuals, which is also affected by the institution. Due to the scale development, anonymity of communication and other features in the modern society, the institution makes people correctly predict the future behavior of others without obtaining the information and understanding the intention of others painstakingly. People can overcome the "knowledge problem”, “economic man” and other problems and avoid various opportunistic behaviors to ensure the necessary social order. The institution is the unconscious product and experience accumulation of successful individual and promote the generation of wider social order, even certain "spontaneous order". The institutional justice is critical to prevent the social disorder caused by the self interest of individuals. However, Hayek's discussion on the "spontaneous order" and institutional justice is still based on the individual liberty, which is the core value of "spontaneous order". Although the formation and maintenance of order cannot leave the authority, the overextended authority will invade the private field and individual liberty. Therefore, the social disorder caused by pursuing the maximization of individual interests should be coordinated by the interaction between individuals, rather than rely on the interference of politics and power. Hayek's spontaneous order theory provides a legitimate basis for the individual liberty and limited 
government and thinks the individual liberty can be guaranteed only by restricting the government's rights.

\section{Enlightenment of Hayek's institutional change idea on institutional change}

1. Mutual supplement of two evolution logics

Since the modern times, with the scientific and technological progress and the prosperous development of the society, the human's good feeling on rational control ability has been improved continuously. Hayek reminds people that almost all the market economy countries have the risk that the politicians "try to design the future of the human", which is caused by the "fatal conceit" of the human rationality. However, it is an ideal state of liberalism to take laissez-faire evolution strategy only according to the "spontaneous order" theory if there is no rational construction.

The author thinks the institution is a complex diversified system and its generation is not single. The single spontaneous evolution institution change path cannot effectively cope with the development trend with increasingly deep division of labor in the society and increasing complex trading. The spontaneous institution formation path makes the institution generation slow, with limited scope of application. Under the complex background with increasing deep division of work in the society, the spontaneous institution generation path often lacks of efficiency if there is no necessary rational construction. "If the economy or other social practice changes rapidly, the habits (the most common form of spontaneous evolution institution under Hayek) will become a burden on progress.” In addition, if the typical forms, such as customs and conventions, of spontaneous evolution institution are not favorable to all people and cannot form the burden or improvement that promotes the whole community or social welfare like what economist Arreau understands.

In the social institution change process, the spontaneously evolutionary progressive change is not the sole desirable method of institutional change and the compulsory leap change is its necessary supplement. The spontaneous evolution and spontaneous construction are the indispensable methods of institutional change, with advantages and disadvantages respectively, and supplement each other. We should conduct analysis according to the actual situation.

\section{Integration of individualism and holism methodology}

Since the publishing of Arreau and Olson's works, the problem with regard to the collective action and collection decision becomes more and more sensitive. In the contemporary institutional analysis theory, the problem concerning the institution is still regarded as a solution of collective problem by the economist of old institution. The institution restricts the individual to help us avoid the negative influences of collective action and make the rationality at the individual level and at the collective level coordinate with each other. To better grasp the realistic world, the new institutional school produces a new methodology by absorbing the advantages of the 
methodology of the opposite side in contending with the theory of old institutional school, that is, integration of individualism and holism methodology, namely, institutional individualism represented by transaction cost. The institutional individualism methodology finds the path of social evolution by endogenesis to realize that there is individual in the whole, there is whole in the individual and the individual and the whole affect each other. This method lays a good methodological foundation for the spontaneous choice and promotion of the institutional development and change.

3. Purpose of institutional change is to realize the integration of formal institution and informal institution

The modern institutionalists divide the institution into informal institution and formal institution, in which the informal institution is embodied as traditional culture, ethics, customs and values that widely exist in all the sectors of the social life of the human in an intangible form and impose subtle influences. The constructive rationalists believe that a small number of elites can conduct compulsory institutional change for the human progress by virtue of their understanding and insight into the society and humanity. The evolutionary rationalists think it is required to rationally conduct liberal dialogue, explanation and game between individuals and reach a consensus by negotiation in the free competition. From the formation of the realistic social order, the social institution change includes not only the evolution path of informal institution, but also the rational construction of formal institution.

Hayek's "spontaneous order" theory tells us that the compulsory institutional change guided by a small number of elites often neglects the individual liberty in the construction of reform of realistic social order. It is allowed to better respect and guarantee the individual liberty only by interaction, dialogue, practice and other methods. The government is required to respect the traditional experience, rationality and innovation upon institutional innovation.

\section{References:}

Hayek. The Constitution of Liberty[M]. Translated by Deng Zhenglai. Beijing: Joint Publishing Press, 1997. 44 Hayek. The Constitution of Liberty[M]. Translated by Deng Zhenglai. Beijing: Joint Publishing Press, 1997. 65 Hayek. The Constitution of Liberty[M]. Translated by Deng Zhenglai. Beijing: Joint Publishing Press, 1997. 204 Lou Hebiao. Composition of Constructive Rationalism in Hayek's Evolution Rationalism[J]. Guangxi Social Sciences, 2005 (6): 36-38

Hayek. The Constitution of Liberty[M] . Translated by Deng Zhenglai. Beijing: Joint Publishing Press, 1997. 65 Posner. Law, Pragmatism and Democracy[M]. Translated by Li Guoqing et al. Beijing: China University of Political Science and Law Press, 2005. 326 